\title{
RELATIVA VULNERABILIDADE. GÊNERO E NATUREZA HUMANA NO FILME "SOB A PELE"
}

\section{Marcos Sardá Vieira ${ }^{1}$}

Resumo: Na visão de um ser alienígena, que estratégias e nuances de vulnerabilidade poderiam ser apontadas para a condição do ser homem e ser mulher na sociedade urbana? Partindo desta curiosidade, este artigo reflete sobre a inversão do que caracteriza a vulnerabilidade humana fora de uma perspectiva consolidada pela dominação masculina, tendo como referência a narrativa do filme "Sob a Pele", de 2013. A partir desta ficção, consideramos a vulnerabilidade do gênero masculino diante da ameaça de uma consciência inumana, que pretende capturar seus corpos. Em contraponto, nas relações que marcam o gênero feminino, consideramos válidos a empatia e o envolvimento emocional para as relações interpessoais como aspectos significativos, que tornam possível amenizar os sintomas da violência e melhorar a convivência social.

Palavras-chave: Gênero; Vulnerabilidade; Ficção; Inumano.

Abstract: The vision of an alien being, what strategies and vulnerability nuances could be given for the condition of being a man and being a woman in urban society? From this curiosity, this article reflects on the reverse featuring human vulnerability outside of a consolidated view by male domination, with reference to the narrative of the film "Under the Skin", 2013. From this fiction, we consider the vulnerability of masculine gender face of the threat of an inhuman consciousness, which wants to capture their bodies. In contrast, the relations that mark the feminine gender, we consider valid empathy and emotional involvement for interpersonal relationships as a significant aspects, which make possible to alleviate the symptoms of violence and improve social coexistence.

Keywords: Gender; Vulnerability; Fiction; Inhuman.

1 Arquiteto, urbanista e professor da Universidade Federal da Fronteira Sul (UFFS). Doutorando Interdisciplinar em Ciências Humanas pela Universidade Federal de Santa Catarina (UFSC). 
Segundo Susana Velázquez (2003), a violência física e simbólica marcada pelo gênero faz das mulheres as principais vítimas, no contexto transnacional de uma sociedade hierarquizada e dominada pelo masculino. Por isso, a ideia de uma mulher solitária, trafegando dia e noite em seu veículo por diferentes áreas urbanas, poderia ser visto como ato de coragem diante da recorrente violência de gênero nos espaços públicos e privados. Entretanto, caso esta figura feminina fosse parte de uma estratégia alienígena para raptar seres humanos, em especial, homens solitários - em que aspectos esta ameaça poderia contribuir para revermos a ideia de vulnerabilidade entre identidades de gênero binárias?

Esta inversão na condição de vulnerabilidade (humana) e violência marcada pelo gênero faz parte da narrativa ficcional apresentada pelo filme "Sob a Pele", lançado em 2013, com base no livro ("Under the Skin") do escritor Michel Faber, apresentando situações de homens sob o risco do desejo despertado pelo contato com uma mulher desconhecida. Tanto no filme quanto no livro, as cenas do cotidiano de uma cidade escocesa servem de cenário para uma estratégia alienígena de capturar corpos de homens com o intuito de extrair suas vísceras. Com direção de Jonathan Glazer e estrelado por Scarlett Johansson, o filme acompanha a perspectiva desta alienígena em cenas onde a vulnerabilidade, de homens e mulheres, é invertida, possibilitando refletir sobre a condição da dominação masculina no espaço de interações sociais. Ao contrário da violência física cometida por homens no ataque direto contra o corpo de representação feminina, a alienígena tira vantagem de sua presença inofensiva e persuasiva, flanando pelos espaços públicos a procura de homens a serem capturados individualmente. Para alcançar seu objetivo, a personagem simula necessitar de ajuda em uma primeira abordagem e, em seguida, induz a vítima ao encontro furtivo, finalizando com a captura do corpo das vítimas em uma armadilha arquitetônica, sem utilizar violência física.

Através desta narrativa ficcional, que permite outro nível de análise da realidade, o objetivo deste artigo é refletir sobre a vulnerabilidade presente no comportamento regular de homens e mulheres no contexto urbano de interações sociais ${ }^{2}$. Esta perspectiva, representada por uma consciência inumana, também nos remete a uma revisão de características associadas à natureza humana.

Ao final, consideramos a importância dos sentimentos e da empatia para as relações interpessoais, tanto com a intenção de amenizar conflitos baseados em comportamentos estereotipados entre homens e mulheres quanto para resgatar os valores mais significativos da boa convivência social.

\section{Gênero, Violência e a Perspectiva Inumana}

No início do filme, após retirar as roupas do único corpo feminino capturado ao longo de toda a estória, a personagem anônima, interpretada por Scarlett Johansson, se prepara para a sua performatividade do gênero feminino no espaço público, adquirindo novas

2 O filme apresenta outras duas locações, fora da área urbana consolidada e desvinculada da estratégia de captura da alienígena, que não serão analisadas neste artigo. 
roupas no shopping center, de maneira a tornar atraente sua aparência visual no primeiro instante do contato com as vítimas.

Todas as suas ações têm como base a estratégia de capturar os homens. Nesta preparação, a personagem circula seu corpo comum no meio da multidão de pessoas, com segurança e normalidade apreendidas ao longo das vivências, diante do simulacro de representações e pessoas a sua volta. O próprio shopping center torna didático para a alienígena o processo de apreender os comportamentos padronizados. A escolha da roupa pelo formato e textura parece ser mais importante aos olhos de um ser alienígena do que o consenso cultural que estabelece características estéticas para a aceitação coletiva. Ao mesmo tempo, o uso de um acessório simples como o batom, revela um artifício fundamental para evidenciar qualquer diferença na identificação do gênero que espera representar. Simone de Beauvoir já nos apresenta esta distinção em sua obra de 1949:

\footnotetext{
"Basta passear de olhos abertos para comprovar que a humanidade se reparte em duas categorias de indivíduos, cujas roupas, rostos, corpos, sorrisos, atitudes, interesses, ocupações são manifestamente diferentes: talvez essas diferenças sejam superficiais, talvez se destinem a desaparecer. O certo é que por enquanto elas existem com uma evidência total" (BEAUVOIR, 1970, pp. 8-9).
}

A distinção entre duas categorias predomina na atualidade. Bastam estes elementos de figurino associados sobre o corpo para instigar uma ideia de desejo sexual diante da condição masculina e heterossexista, em instituir ações e comportamento em acreditar que a mulher deve estar disponível para o homem (CAPPELLE et al, 2004). Este pensamento está presente na perspectiva da violência (física e simbólica) contra as mulheres em um contexto transnacional e transcultural (GOMES, 2008), independente de raça e classe. De acordo com Adrienne Rich (2010) esta sujeição é presente nas estruturas sociais e culturais, que identificam as mulheres, primariamente, como seres sexuais a serviço dos desejos dos homens.

Por esta convenção majoritária, torna-se coerente compreender, a partir do filme, que a figura de uma mulher bem vestida, no controle de um veículo e tendo como fundo uma área urbana consolidada, não representa uma ameaça. Na brecha deste olhar humano essencialista surge, justamente, a oportunidade da alienígena em desempenhar sua função de capturar corpos masculinos sem levantar suspeitas. Mas, de que maneira a estratégia alienígena interpreta e tira partido das diferenças de vulnerabilidade quando transforma em vantagem o que, normalmente, é visto como desvantagem na relação de dominação entre os sexos?

Antes de interpretar esta pergunta, talvez, seja necessário apresentar o que caracteriza as distinções entre homens e mulheres a partir dos estudos de gênero. De acordo com Miriam Pillar Grossi (1998) quando falamos de sexo, referimo-nos apenas a dois sexos: homem e mulher (ou macho e fêmea) - dois sexos sobre os quais "apoiamos" nossos significados do que é ser homem ou ser mulher. A associação ao sexo biológico fêmea e macho é considerado papel de gênero em determinadas culturas. Porém, os papéis de gênero não são biologicamente determinados e são mutáveis cultural e historicamente. Por isso, a identidade de gênero é algo mais complexo porque remete à constituição do sentimento individual de identidade. 
Para Judith Butler (2002), não existe uma pré-condição (ou um discurso prévio) do sexo que atue com referência estável na construção cultural do gênero. A autora questiona quais as forças que fazem o corpo se materializar como sexuado e como devemos entender a materialidade do sexo e do corpo como exterioridade repetida e violenta de uma inteligibilidade cultural. A partir disso, Butler questiona: o que diferencia a validade de um corpo diante de outros e por quê? Tudo estaria vinculado na maneira como a heterossexualidade hegemônica modela a sexualidade.

Problematizando as questões entre o gênero e o sexo em outra publicação, Butler (2015) analisa a variação das categorias de gênero que são assumidas ou absorvidas pela cultura, no sentido de que ninguém nasce com o gênero. Por outro lado, para esta filósofa, o sexo é uma condição que surge com o nascimento, qualificando o ser humano. Enquanto para Beauvoir (1970 [1949]), “o sexo é imutavelmente um fato, mas o gênero é adquirido". Nesta análise, Butler (2015) confirma esta afirmação de Beauvoir destacando a distinção entre sexo e gênero. Mesmo que o sexo seja uma condição fixa e o gênero um aspecto adquirido, nada pode afirmar, segundo Butler (2015), que o sexo causa o gênero. Diante disso, surge a seguinte consideração: “a categoria 'mulher' não é necessariamente a construção cultural do corpo feminino, e 'homem' não precisa necessariamente interpretar os corpos masculinos” (BUTLER, 2015, p. 194). Ou seja, se o gênero não está limitado ao sexo enquanto construção da identidade do sujeito, isso significa que podemos interpretar culturalmente o corpo sexuado de várias maneiras distintas, sem estar limitado à visão dualista do sexo. Portanto, o gênero pode compor formas de expressão que vão além dos limites binários estabelecidos pela cultura e "pelo aspecto binário aparente do sexo" (BUTLER, 2015, p. 195).

Ainda assim, o comportamento que diferencia homens e mulheres é compulsório na sociedade. Nesta condição paradoxal de ocupar o lugar social do feminino como estratégia de subversão criminal, a figura alienígena no filme "Sob a Pele" revela, na verdade, o lado de vulnerabilidade social dos homens diante da sua condição de dominação.

O questionamento da posição do homem como vítima do seu próprio desejo também é parte da realidade cotidiana. É comum a interpretação da violência contra a mulher transcorrer em um processo de transformação subliminar, onde o agressor se torna a vitima de suas vitimas, sustentando a ideia de que a mulher, passiva e vitimizada, deveria recorrer aos mecanismos de defesa e antecipação das intenções de agressão para evitar o ocorrido. Ou seja, a perspectiva baseada no argumento machista e patriarcal da condição masculina tornam os homens, meliantes da violência de gênero, vitimas dos seus desejos pelas mulheres, principalmente, quando elas desafiam o território e a autoridade masculina (VELÁZQUEZ, 2003). Seria o caso de uma funcionária, sofrendo assédio sexual de seu chefe no trabalho porque resolveu usar mini-saia. Ou de uma estudante, que resolveu andar sozinha na rua onde já deveria saber do risco de violação. E, ainda, da esposa, que poderia prever a atitude agressiva do marido diante de uma cena de ciúmes. Essa seria a violência vista sob a perspectiva masculina, tanto daqueles que cometem a violência quanto dos que naturalizam estes efeitos como parte da relação entre homens e mulheres.

Entretanto, em uma perspectiva que foge do caráter humano, como na narrativa ficcional do filme, observamos aspectos que expõe a vulnerabilidade de homens em suas interações urbanas, justamente, pelo excesso de confiança de um domínio dado com previsível. 
O filme apresenta este paradoxo da vulnerabilidade entre homens e mulheres quando a alienígena trafega dentro do carro, olhando as pessoas nas ruas, de maneira indiscriminada. Em algumas destas sequências, a narrativa revela o grande número de mulheres participando do espaço público e compondo a multidão nas ruas. Mas, porque as mulheres não fazem parte da estratégia de captura alienígena?

O filme torna claro a presença de mulheres neste ambiente de caça aos humanos. Na narrativa, boa parte destas mulheres encontra-se envolvida em atividades (como atendendo ao telefone e fazendo compras) ou acompanhadas. Ao contrário do perfil dos homens, o retrato das mulheres no filme demonstra uma condição para o gênero feminino mais articulado em suas redes sociais, principalmente, quando participam das atividades no espaço público. Diferente da condição dos homens, que se expõem mais em percursos solitários pelas ruas da cidade. Mesmo sem uma explicação prévia da narrativa do filme, fica muito claro a adaptação da estratégia de captura e sobrevivência alienígena no filme. Quando estes indivíduos, masculinos e solitários, demonstram algum vínculo pré-estabelecido (como estar indo ao encontro de alguém, ou ter pessoas conhecidas nas proximidades) a alienígena desiste da abordagem e continuava seu deslocamento evitando levantar suspeitas ${ }^{3}$. Ou seja, em uma seleção da melhor oportunidade de captura dos corpos humanos ela considera os aspectos de vulnerabilidade diante da maior liberdade de atuações e sensação de segurança dos homens no espaço público. Uma perspectiva que aponta a vulnerabilidade dos homens e de qualquer categoria social que acredita dominar as situações de risco no espaço urbano.

Para Pierre Bourdieu (2012), a dominação masculina tornou-se uma evidência que determina a qualidade das relações sociais, atribuindo privilégios materiais, culturais e simbólicos aos homens heterossexuais e definindo relações desiguais entre homens e mulheres. "A supremacia masculina ditada pelos valores do patriarcado atribui um maior valor às atividades masculinas em detrimento das atividades femininas" e legitima "o controle da sexualidade, dos corpos e da autonomia feminina" quando estabelece estereótipos aos papeis sexuais e sociais onde o caráter masculino obtém vantagens (NARVAZ e KOLLER, 2006, p. 50). Entretanto, a condição cultural e ideológica estabelecida pela dominação masculina também representa um meio de tornar invisível as suas falhas. Interpretando este contexto ideológico na estrutura do sistema de vida da civilização a partir de Slavoj Zizek (2003), podemos considerar que quanto mais a liberdade é aparente, mais fácil torna-se o controle sob determinado segmento da população, considerando outras categorias na estrutura de hierarquia social.

Talvez, por isso, a estratégia de uma alienígena tenha surtido efeito em se camuflar com a aparência física da fragilidade feminina por compreender que esta performatividade não levanta suspeita. Inclusive, é interessante notar que esta representação não agressiva, enquanto estereótipo esperado do comportamento feminino transparece no comportamento da personagem, que não é responsável, diretamente, pela dominação do corpo das vítimas. A alienígena sob a pele de mulher torna-se apenas a isca dentro de um mecanismo

3 Ao longo da narrativa do filme, fica claro o fator de risco para a alienígena na medida em que sua figura também está inserida na condição de uma identidade feminina, sujeita a violência física e simbólica dos homens ao longo de seus encontros furtivos pela cidade. Seu corpo inumano, sob a pele da mulher, não demonstra vantagem ou maior aptidão física diante do corpo humano. Por esta razão, talvez, a estratégia de não levantar suspeitas seja importante para o sucesso da ação de capturar seres humanos, em particular homens, que poderiam reagir com violência. 
mais complexo, que utiliza a cidade escocesa e a arquitetura de uma casa (onde leva suas vitimas para o suposto encontro furtivo) para esconder seus atos ilícitos e inumanos. Um segundo alienígena, na figura de um motoqueiro, mantém a retaguarda para o encobrimento de pistas, que poderiam revelar o sumiço dos homens.

A discreta participação de um ser estranho e alienígena no contexto de uma zona urbana, relativamente densa, revela, por si só, um imaginário de vulnerabilidades imprevisíveis. Este ponto de vista alienígena em sua estratégia de ação nos permite analisar a reprodução de valores culturais não apenas para questionar a restrição de atuações na concepção de gêneros binários, mas os próprios aspectos relativos ao conceito de natureza humana.

No filme, os lugares com poucas pessoas ou onde costuma existir maior presença de homens, tornavam-se boas oportunidades para a abordagem da alienígena. Em uma locação na praia, por exemplo, a alienígena aguardava na areia o encontro com um homem, que estava saindo do mar (que iremos identificar como surfista, por ele utilizar uma roupa de borracha) para iniciar uma fraca abordagem, insinuando seu interesse por um encontro furtivo, com base nos seus contatos anteriores. Porém, o surfista demonstra menos interesse diante desta abordagem feita por uma desconhecida. Suas atitudes demonstram outros valores diante da vida em sua predisposição em ajudar outras pessoas.

Em uma cena rápida que segue, o surfista interrompe a conversa com a alienígena para socorrer um casal, que se encontra a deriva no mar revolto. Ele sai correndo na praia em direção ao casal, entra na água e resgata apenas o homem. Nesta ocasião, perde-se o enquadramento da mulher dentro d'água. O surfista carrega o homem até a beira do mar e, exausto, se joga na areia, enquanto o homem resgatado retorna para o mar na ideia fixa de resgatar a mulher. A cena se volta, então, para o surfista jogado na areia enquanto a alienígena vai ao seu encontro, novamente, pela borda d'água. Detalhe interessante: ela continua usando a mesma combinação do traje no shopping center, enquanto caminha com os sapatos na água. Em seu único movimento de relativa agressividade ao longo da narrativa, a alienígena bate com uma pedra na cabeça do surfista para imobiliza-lo totalmente, como se fosse uma situação extrema em garantir a captura do corpo. Ela o arrasta para dentro do veículo com dificuldade e, supõem-se pelas cenas seguintes, que obtém sucesso na apreensão da vítima.

$\mathrm{O}$ fato mais intrigante nesta sequência de captura é quando o motoqueiro aparece na mesma cena da praia mais tarde, em período noturno, para resgatar a toalha do surfista, que ficou jogada no chão, antes deste fazer o resgate no mar. Em destaque nesta cena surge o choro do bebê de colo, que acompanhava o casal, ainda sentado na praia (que ficou sozinho durante todo o período depois que seus pais se afogaram na água), enquanto o motoqueiro vai em sua direção para pega a toalha e voltar, sem nem mesmo se preocupar com a criança. A cena foca na criança órfã chorando, sem autonomia e abandonada naquela praia noturna e deserta. Resgatar a criança estava fora de qualquer cogitação para a perspectiva alienígena.

A presença destes personagens revelam atitudes de imparcialidade extrema diante de sentimentos como empatia, prazer, alegria, ansiedade, constrangimento e medo. Sentimentos associados a manutenção interpessoais e, ao mesmo tempo, demonstram características elevadas da natureza humana intrínseca. Esta atitude apresentada pelo filme, de negação ao humano (CAVARERO e BUTLER, 2007), também está relacionada à ausência de fundamentos éticos pela desvalorização da vida, que teria importância apenas como meio para se alcançar outros fins. 


\section{Considerações Finais}

Através desta reflexão queremos evidenciar o quanto às emoções e a empatia predise põem condições de proteção aos seres humanos a partir de uma perspectiva alienígena e ficcional. De acordo com Adriana Cavarero e Judith Butler (2007) o inumano entra, justamente, como atributo de negação daquilo que é humano, como algo indescritível e perturbador para o reconhecimento humano. Ao mesmo tempo, são aspectos que relativizam a condição humana e perturbam nossas concepções morais e emocionais.

Consideramos que, os laços sentimentais entre as pessoas refletem benefícios nem sempre racionais. Apesar da valorização da razão e do menosprezo para as emoções, "não é pelo dinheiro, o sucesso ou a fama o que mais faz bem às pessoas, mas o tempo que elas passam com os amigos e a família” (DE WAAL, 2010, p. 29). Claro que a representação ficcional do ser alienígena desloca o inumano para além de qualquer natureza terrestre e nem mesmo identificada pelo código genético das espécies do planeta. Assim como, a própria natureza selvagem e terrestre, que também extrapola a conceito do humano, segundo Cavarero e Butler (2007). Em muitos aspectos a natureza ainda é desconhecida e distante da interferência humana, com seus limites cognitivos básicos, que nos impedem de imaginar outras possibilidades para as condições de vida e sobrevivência (WERNER, 1997). Talvez, até mesmo com indivíduos da espécie humana a dissimulação tende a torna-se um artifício. Ainda assim, é pela empatia e pelas emoções compartilhadas que a confiança e a seguridade consolidam-se como vínculos profundos na relação entre as pessoas, independente do caráter vinculado ao gênero.

\section{Referências}

BEAUVOIR, Simone de. O Segundo Sexo: fatos e mitos. $4^{\text {a }}$ Ed. São Paulo: Difusão Europeia do Livro, 1970 (1949).

BOURDIEU, Pierre. A Dominação Masculina. 11 a ed. Rio de Janeiro: Bertrand Brasil, 2012.

BUTLER, Judith. Problemas de Gênero: feminismo e subversão da identidade. Tradução de Renato Aguiar. 8a ed. Rio de Janeiro: Civilização Brasileira, 2015.

BUTLER, Judith. Cuerpos que Importan: sobre los límites materiales y discursivos del "sexo". 1ªd. Buenos Aires: Paidós, 2002.

CAPELle, Mônica C. A. MELO, Marlene C. de O. BRITO, Maria J. M. BRITO, Mozar J. de. Uma Análise da Dinâmica do Poder e das relações de Gênero no Espaço Organizacional. In: ERAeletrônica, V. 3, No 2, Art. 22. São Paulo: FGV, jul-dez., 2004.

CAVARERO, Adriana. BUTLER, Judith. Condição Humana Contra "Natureza". Revista Estudos Feministas. 15(3). Set-dez, 2007, pp. 647-662. 
DE WAAL, Frans. A Era da Empatia: lições da natureza para uma sociedade mais gentil. São Paulo: Companhia das Letras, 2010.

GOMES, Romeu. A Dimensão Simbólica da Violência de Gênero: uma discussão introdutória. Athenea Digital. No 14, 2008, pp. 237-243. Disponível em https://dialnet.unirioja.es/servlet/ articulo? codigo $=2736191$ consulado em setembro de 2016 .

GROSSI, Miriam Pillar. Identidade de Gênero e Sexualidade. In: Antropologia em Primeira Mão. Florianópolis, 1998, pp. 1-18. Disponível em http://miriamgrossi.paginas.ufsc.br/files/2012/03/grossi_ miriam_identidade_de_genero_e_sexualidade.pdf consultado em setembro de 2016.

NARVAZ, Martha Giudice. KOLLER, Sílvia Helena. Famílias e Patriarcado: da prescrição normativa à subversão criativa. In: Psicologia \& Sociedade. 18(1). Jan/abr. 2006, pp. 49-55. Disponível em http:// www.scielo.br/pdf/psoc/v18n1/a07v18n1 consultado em setembro de 2016.

RICH, Adrienne. Heterossexualidade Compulsória e Existência Lésbica. Tradução Carlos Guilherme do Valle. Revista Bagoas. No 5. Natal: UFRN, 2010, pp. 17-44.

VELÁZQUEZ, Susana. Violencias Cotianas, Violencia de Género: escuchar, aprender, ayudar. Ediciones Paidos Iberica, 2003.

WERNER, Dennis. O Pensamento de Animais e intelectuais: evolução e epistemologia. Florianópolis: Editora da UFSC, 1997.

ZIZEK, Slavoj. Bem-Vindo ao Deserto do Real! Cinco ensaios sobre o 11 de setembro e datas relacionadas. Coleção Estado de Sítio. Boitempo Editoral, 2003. 